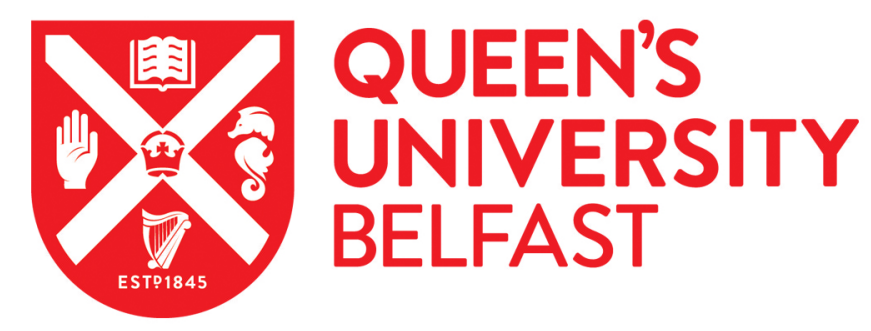

\title{
Phase morphology and mechanical properties of polyetherimide modified epoxy resins: A comparative study
}

Ma, H., Aravand, M. A., \& Falzon, B. G. (2019). Phase morphology and mechanical properties of polyetherimide modified epoxy resins: A comparative study. Polymer, 179, [121640].

https://doi.org/10.1016/j.polymer.2019.121640

\section{Published in:}

Polymer

\section{Document Version:}

Peer reviewed version

Queen's University Belfast - Research Portal:

Link to publication record in Queen's University Belfast Research Portal

Publisher rights

(C) 2019 Elsevier Ltd.

This manuscript version is made available under the CC-BY-NC-ND 4.0 license http://creativecommons.org/licenses/by-nc-nd/4.0/,which permits distribution and reproduction for non-commercial purposes, provided the author and source are cited.

\section{General rights}

Copyright for the publications made accessible via the Queen's University Belfast Research Portal is retained by the author(s) and / or other copyright owners and it is a condition of accessing these publications that users recognise and abide by the legal requirements associated with these rights.

Take down policy

The Research Portal is Queen's institutional repository that provides access to Queen's research output. Every effort has been made to ensure that content in the Research Portal does not infringe any person's rights, or applicable UK laws. If you discover content in the Research Portal that you believe breaches copyright or violates any law, please contact openaccess@qub.ac.uk. 


\section{Accepted Manuscript}

Phase morphology and mechanical properties of polyetherimide modified epoxy resins: A comparative study

Hong Ma, M. Ali Aravand, Brian G. Falzon

polymer

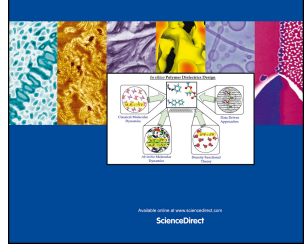

PII:

S0032-3861(19)30624-X

DOI:

https://doi.org/10.1016/j.polymer.2019.121640

Article Number: 121640

Reference: JPOL 121640

To appear in: Polymer

Received Date: 27 March 2019

Revised Date: 5 July 2019

Accepted Date: 8 July 2019

Please cite this article as: Ma H, Aravand MA, Falzon BG, Phase morphology and mechanical properties of polyetherimide modified epoxy resins: A comparative study, Polymer (2019), doi: https:// doi.org/10.1016/j.polymer.2019.121640.

This is a PDF file of an unedited manuscript that has been accepted for publication. As a service to our customers we are providing this early version of the manuscript. The manuscript will undergo copyediting, typesetting, and review of the resulting proof before it is published in its final form. Please note that during the production process errors may be discovered which could affect the content, and all legal disclaimers that apply to the journal pertain. 
Modification of epoxy resins with different functionalities by thermoplastic (TP)
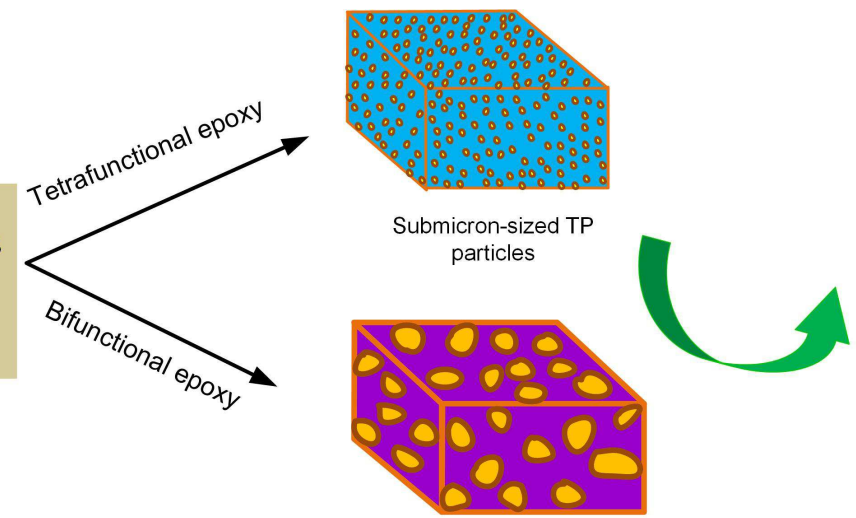

Micron-sized TP particles

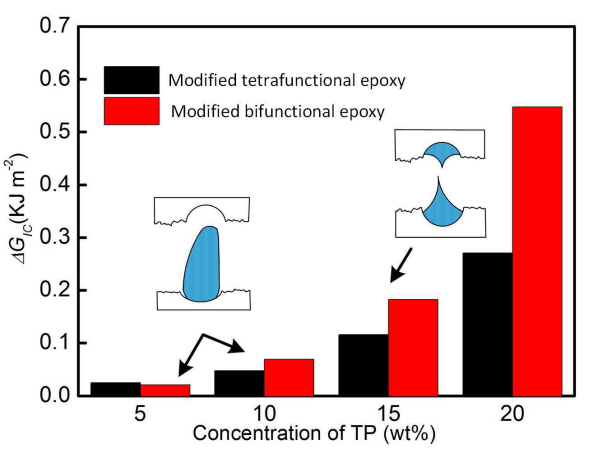




\title{
Phase morphology and mechanical properties of polyetherimide modified epoxy resins:
}

\section{a comparative study}

\author{
Hong Ma ${ }^{\mathrm{a}}$, M. Ali Aravand ${ }^{\mathrm{a}, \mathrm{b}^{*}}$ and Brian G. Falzon ${ }^{\mathrm{a}, \mathrm{b} *}$ \\ ${ }^{a}$ Advanced Composites Research Group (ACRG), School of Mechanical and Aerospace Engineering, \\ Queen's University Belfast, UK, BT9 5AH \\ ${ }^{b}$ Northern Ireland Advanced Composite and Engineering (NIACE) Centre, Airport Road, Belfast, UK, \\ BT3 9DZ
}

\begin{abstract}
This paper presents a detailed study of the relationship between phase morphology and fracture toughness of two types of thermoplastic modified epoxy resins, a tetrafunctional and a bifunctional type. The reaction-induced phase separation of the thermoplastic (TP) during curing leads to distinct morphologies, depending on the modifier content and the functionality of the matrix. This, in turn, impacts the fracture toughness of modified epoxy resins. A transition from a particulate to a cocontinuous morphology is observed at sufficiently high TP content (20 wt $\%)$ in both epoxy systems. Thermoplastic phases exhibit a significant level of plastic deformation during crack propagation followed by tearing or debonding, depending on the composition. This, in addition to the formation of shear bands in the matrix, is the most dominant energy dissipation mechanism. Higher viscosity and cross-link density of the tetrafunctional epoxy result in the formation of uniformly distributed submicron-sized thermoplastic particles, where the limited diffusion growth of thermoplastic phase, following the onset of phase separation, is further restricted.
\end{abstract}

Key words: Phase morphology, fracture toughness, reaction-induced phase separation, crack bridging, shear banding

\footnotetext{
* Corresponding authors at: School of Mechanical and Aerospace Engineering, Queen's University Belfast, UK, BT9 5AH.

E-mail: b.falzon@qub.ac.uk (Brian G. Falzon), m.aravand@qub.ac.uk (M. Ali Aravand).
} 


\section{Introduction}

Epoxy resin is one of the most widely used matrix materials in fibre reinforced polymer (FRP) composites. This is predominantly due to its relatively high stiffness, superior compatibility and adhesion, and chemical resistance. Epoxy resins with higher functionalities such as tetraglycidyl diamino diphenyl methane (TGDDM) also exhibit high temperature performance [1-3]. However, the intrinsic brittleness of cured epoxy resins, arising from the high degree of cross-linking during curing, often leads to low resistance against crack formation and propagation. This is reflected in the commonly reported modest values of the in-plane and out-of-plane matrix-dominated properties of the resulting FRP composites, especially interlaminar fracture toughness, transverse strength, and interlaminar shear strength of a laminate [4,5]. Various approaches have been proposed to mitigate this brittleness. The inclusion/formation of microscale heterogeneities is widely reported as one of the most effective approaches. Matrix heterogeneities, or tougheners, in the form of micro- or nano"inclusions" can induce various energy dissipation mechanisms thereby limiting the onset and propagation of cracks. "Inclusions" encompass wide range of materials from rigid to soft organic or inorganic materials in different sizes and shapes. They may be added to the resin either as pre-formed particles or form/precipitate during curing in an irreversible thermodynamic process often referred to as reaction-induced phase separation (RIPS). The latter, which is applied to polymeric modifiers, has been shown to be more effective in enhancing the fracture toughness of epoxies in comparison with systems where pre-formed particles were used [6]. In this case, polymer modifiers are initially dissolved in the epoxy resin forming a homogeneous solution. Modifier particles then phase-separate following the start of the curing reaction till the gelation of epoxy resin. Thermodynamic characteristics of the RIPS process, including the underlying mechanisms and phase morphology, have been widely studied [7-9].

Rubber tougheners, including reactive liquid monomers and pre-formed core-shell rubbers (CSR), are known to be able to provide the highest increase in fracture toughness of epoxy resins [9-11]. However, rubber tougheners can significantly compromise the mechanical properties and glass transition temperature ( $T g$ ) of epoxy resins. In one case, for instance, addition of a CSR toughener 
with 22 vol.\% resulted in a more than $25 \%$ loss in tensile strength of a diglycidylether of bisphenol A (DGEBA) epoxy resin [10]. Ratna [12] reported a $20 \%$ drop in the $T_{g}$ of DGEBA epoxy upon the addition of 20 parts by weight ( $\mathrm{pbw}$ ) of epoxy rubber toughener. Moreover, in comparison with the bifunctional epoxy resins, such as DGEBA, rubber toughening of multifunctional epoxy resins such as TGDDM and triglycidyl-p-aminophenol (TGPAP), can be less effective. This could be explained by the fact that major energy dissipation mechanisms in rubber modified epoxy systems are shear banding of epoxy matrix and cavitation of rubber particles along the crack propagation path, both of which would greatly depend upon the ductility of the epoxy matrix [13,14]. Engineering thermoplastics on the other hand, have attracted considerable attention in view of their effectiveness in increasing the fracture toughness of epoxy resins, with no or limited effects on other mechanical properties and high temperature performance of the epoxy resins [14-16].

In thermoplastic (TP) modified epoxy blends, RIPS can result in different types of morphologies including particle/matrix, co-continuous and phase-inverted, depending on variables such as composition of the blend [17,18], molecular weight of thermoplastic [17,19], curing profile [20-22] and existence of other additives (such as graphene oxide [23] and $\mathrm{SiO}_{2}[24,25]$ ). This has been shown to have significant impact on the fracture toughness of the resulting blends $[17,18,26]$. Increasing the weight fraction of the TP modifier could turn a particle/matrix morphology into a co-continuous type or even a phase-inverted system. In some cases, it would even be possible to achieve various morphologies without changing the composition and just through modification of the curing conditions. Cho et al. [27] produced a phase-separated system with a co-continuous morphology at a relatively low modifier content by lowering the curing temperature and extending the curing time. In this case, a particulate morphology was realised at higher curing temperatures at similar modifier content. Our preliminary investigations revealed that besides the widely studied effects of the processing conditions on phase separation, the functionality of the resin also plays a major role in the phase separation process and hence the morphological characteristics of the resulting multiphase system. This would, in turn, have serious implications on the properties of the toughened resin including fracture behaviour. Despite of the importance of this matter, especially in consideration of 
their potential consequences on the properties of the resulting FRP composites, the literature available on the subject is quite scarce. Hodgkin et al. [28], after reviewing results obtained by other researchers, came to the conclusion that the thermoplastic toughening of epoxy resins with a higher number of functional groups would be more effective. Nevertheless, the reviewed studies employed different curing profiles, which may also affect the fracture toughness of modified epoxy systems.

A lack of sufficient information on the role of the matrix underscores the necessity of a systematic study on phase separation and morphological characteristics of TP modified epoxies with different epoxide content and their relationship with the resulting fracture behaviour. From an application perspective, epoxy resins with a higher number of functional groups, and hence higher cross-link density, exhibit superior mechanical and thermal properties following curing with a hardener [7,29]. The higher epoxide content of these resins often results in further limitations in ductility, making the TP tougheners a better choice since, as mentioned earlier, unlike rubber modifiers, the dominant toughening mechanism with engineering TPs would be less dependent on the matrix ductility.

In the present work, an engineering thermoplastic, polyetherimide (PEI), is used to modify two types of epoxy resins, namely diglycidylether of bisphenol A (DGEBA) and tetraglycidyl diamino diphenyl methane (TGDDM). DGEBA is a commonly-used epoxy resin in FRP composites and adhesives. TGDDM is a tetrafunctional epoxy used in applications requiring higher temperature performance and mechanical properties. The phase morphology and mechanical properties of the modified resin systems were analysed with a focus on the evolution of the phase morphology of modified epoxy blends and the underlying mechanisms. Mode-I fracture toughness of the cured systems was then measured and the fracture surfaces were examined to gain further insight into the energy dissipation mechanisms.

\section{Materials and method}

\subsection{Materials}

The two epoxy monomers used in this study are a diglycidyl ether of bis-phenol A (DGEBA) with an epoxy equivalent weight (EEW) of 170 g/mol (D.E.R. 332, Sigma-Aldrich), and a tetraglycidyl-4,4'- 
diaminodifenylmethaan (TGDDM) with an EEW of to $105.5 \mathrm{~g} / \mathrm{mol}$ (Araldite MY $72 \mathrm{CH}$, Huntsman).

Both epoxy systems were cured using a high temperature curative, 4,4'-methylenebis-(3-chloro 2,6diethylaniline) (MCDEA) with molecular weight of $379.38 \mathrm{~g} / \mathrm{mol}$ from Lonzacure. The thermoplastic material used in this study is polyetherimide supplied by Sigma-Aldrich. PEI has a glass transition temperature $(T g)$ of $212^{\circ} \mathrm{C}$ and a density of $1.27 \mathrm{~g} / \mathrm{cm}^{3}$ at $25^{\circ} \mathrm{C}$ with molecular weight of $592.61 \mathrm{~g} / \mathrm{mol}$. Dichloromethane (DCM) from Sigma-Aldrich, was used to dissolve PEI when needed.

\subsection{Sample preparation}

For the fabrication of PEI-modified TGDDM, the required quantity of PEI was dissolved in DCM followed by mixing with epoxy monomer. The obtained solution was transferred to a silicone oil bath preheated to $180^{\circ} \mathrm{C}$ and stirred for $2-3$ hours to evaporate the solvent. Any remaining traces of solvent were removed by degassing under vacuum, before the addition of MCDEA hardener. After further degassing, the mixture was then poured into a preheated mould cavity and cured for 2 hours at $200^{\circ} \mathrm{C}$. This was followed by a 2-hour long post-curing step at $220^{\circ} \mathrm{C}$ to ensure complete vitrification. The resulting samples of TP modified epoxy system had $0,5,10,15$ and $20 \mathrm{wt} \%$ PEI, denoted hereafter as TGP0, TGP5, TGP10, TGP15, and TGP20. A Similar procedure was followed to prepare TP modified bifunctional epoxy (DGEBA) systems, indicated in the text as DP0, DP5, DP10, DP15 and DP20 for the above-mentioned PEI compositions.

\subsection{Characterisation method}

The effect of TP modification on cure behaviour of both epoxy systems was investigated using isothermal differential scanning calorimetry (DSC, DSC-6, Perkin Elmer) of the resin mixtures at the curing temperature $\left(200^{\circ} \mathrm{C}\right)$. The samples were then cooled down rapidly before conducting the second (non-isothermal) DSC measurement, sweeping temperatures up to $400^{\circ} \mathrm{C}$ at a heating rate of $10^{\circ} \mathrm{C} / \mathrm{min}$ to obtain the residual heat, based on a dynamic scan.

The degree of conversion as a function of time, $\alpha(t)$, is then calculated using the following relationship: 


$$
\alpha(t)=\Delta H_{t} /\left(\Delta H_{\text {iso }}+\Delta H_{\text {residual }}\right)
$$

where $\Delta H_{t}$ is the heat under the isothermal curve at time $t, \Delta H_{i s o}$ and $\Delta H_{\text {residual }}$ are the heat generation measured by the isothermal and dynamic scans, respectively.

The conversion rate, $\lambda$, can be obtained by differentiating the degree of conversion $\alpha(t)$ with respect to time, $t$ :

$$
\lambda=\frac{d \alpha(t)}{d t}
$$

The moduli of the resin systems were measured by dynamic mechanical analysis (DMA, Tritec 2000, Triton Technology Ltd) in bending mode, using a dual-cantilever fixture. Specimens with a final dimension of $45 \mathrm{~mm} \times 8 \mathrm{~mm} \times 4 \mathrm{~mm}$ were machined from the cured sheets. DMA tests were carried out at a frequency of $1 \mathrm{~Hz}$ and a constant heating rate of $3^{\circ} \mathrm{C} / \mathrm{min}$, sweeping temperatures between 30 to $300^{\circ} \mathrm{C}$ under a displacement amplitude of $0.1 \%$. The cross-link density, defined as moles of elastically effective network chains per unit volume, was calculated based on an approximation of the kinetic theory of rubber elasticity [30,31]:

$$
v_{e}=\frac{E^{\prime}}{3 g R T}
$$

Where $E^{\prime}$ is the storage modulus of the blend obtained from DMA at temperature $T ; T$ is the temperature in Kelvin well above $T_{g}$; Storage modulus of the modified epoxy resin at $543 \mathrm{~K}\left(270^{\circ} \mathrm{C}\right)$, $553 \mathrm{~K}\left(280^{\circ} \mathrm{C}\right)$ and $563 \mathrm{~K}\left(290^{\circ} \mathrm{C}\right)$ were selected to obtain the cross-link density; $R$ is the universal gas constant; $g$ is the so called front factor, related to the functionality of the system. Here values of 1 and 0.7 were chosen for DGEBA and TGDDM systems, respectively [32,33].

A TA Instrument AR2000 rheometer with a $25 \mathrm{~mm}$ parallel-plate setup was utilised to obtain the viscosity of the modified epoxy resins as a function of temperature. Rheological measurements were carried out in the oscillatory mode with a frequency of $1 \mathrm{~Hz}$, and strain value of $1 \%$ for all experiments. The gap between the two plates was in the range of 800 to $1000 \mu \mathrm{m}$. The temperature was increased from room temperature to $200^{\circ} \mathrm{C}$ at a heating rate of $3^{\circ} \mathrm{C} / \mathrm{min}$. 
Surface topology of the cryo-fractured surfaces was investigated using atomic force microscopy (AFM, Cypher ES system, Asylum Research) in tapping mode at a scan rate of $1 \mathrm{~Hz}$. The AFM data was processed using the Gwyddion software. After importing the original AFM data, the greyscale AFM images were generated and the size distribution and volume fraction of the thermoplastic phase were obtained using the tool provided by the software. A field emission scanning electron microscope (SEM, JSM-6500F, JEOL) was also used for further investigation of the fracture surfaces of the blends. All fracture surfaces were sputter-coated with gold, prior to the analysis, to prevent the buildup of electrical charge.

\subsection{Mode-I fracture toughness test}

Single edge notched bending (SENB) specimens were prepared according to ASTM D5045 to determine the plane strain critical stress intensity factor, $K_{I C}$, as well as the critical strain energy release rate, $G_{I C}$. Specimens were cut from the bulk material based on the requirements of the standard. A V-notch with an approximate depth of $1.8 \mathrm{~mm}$ was machined at the bottom centre of the specimens where a sharp pre-crack was created using a drop-weight setup equipped with a sharp blade. The total length of the cracks, including the V-notch, was in agreement with the requirements of the standard where $0.45<\frac{a}{w}<0.55$ (' $a$ ' is the crack length and ' $w$ ' is the specimen width). An Instron universal testing machine with a load cell of $100 \mathrm{~N}$ with a three-point bending setup was used to perform the tests at a constant displacement rate of $1 \mathrm{~mm} / \mathrm{min}$. The critical stress intensity factor was calculated based on the following relationship:

$$
K_{I C}=\frac{P}{b w^{\frac{1}{2}}} f(\alpha)
$$

where $P$ is the peak load, $b$ and $w$ are the thickness and width of the specimens respectively, and $f(\alpha)$ is a geometric constant. The energy release rate was calculated using the relationship between $G_{I C}$, $K_{I C}$, the tensile modulus, $E$, and the Poisson's ratio, $v$ :

$$
G_{I C}=\frac{K_{I C}^{2}}{E}\left(1-v^{2}\right)
$$


Tensile testing of the modified epoxy resins was carried out at a crosshead speed of $3 \mathrm{~mm} / \mathrm{min}$. Digital image correlation (DIC) was then used to obtain the strain maps during tensile tests for accurate measurement of tensile modulus, $E$, and the Poisson's ratio, $v$.

\section{Results and discussion}

\subsection{Phase morphology of the thermoplastic modified epoxy systems}

Fig. 1 compares the AFM micrographs of the thermoplastic modified epoxy systems at different TP contents. Both unmodified bifunctional and tetrafunctional epoxy resins (DP0 and TGP0, Fig. 1a and 1b) exhibit rather similar featureless fracture surfaces. Phase-separated PEI particles are visible in both cases at $5 \mathrm{wt} \%$ TP (DP5 and TGP5). This particulate morphology is maintained up to a TP content of $15 \mathrm{wt} \%$.

The bright spots indicated by the arrows in Fig. 1 are the PEI particles being uniformly dispersed in the continuous epoxy-rich domains. These particles however have distinctly different sizes even at similar compositions when the two types of epoxy systems are compared. The TP particles phaseseparated in the tetrafunctional epoxy system (TGP5, TGP10 and TGP15) are submicron sized whereas in the case of the bifunctional epoxy (DP5, DP10 and DP15), the PEI particles are noticeably larger $(\geq 1 \mu \mathrm{m})$. Increasing the content of the thermoplastic for each type of epoxy system results in a subsequent increase in the particle size in both type of systems. The average particle size ranges from $26.8 \pm 5.89 \mathrm{~nm}$ at $5 \mathrm{wt} \%$ PEI in the tetrafunctional epoxy (TGP5) up to $101 \pm 13.3 \mathrm{~nm}$ in TGP15. In the case of bifunctional epoxy system, this ranges from an average of $1.00 \pm 0.29 \mu \mathrm{m}$ in DP5 to $1.24 \pm 0.29$ $\mu \mathrm{m}$ in DP15, as shown in Table 1. In order to identify whether the thermoplastic was fully phaseseparated after the curing reaction, the volume fraction of the thermoplastic in the matrix, calculated from the initial weight content, was compared with the one measured directly from the AFM images as listed in Table 1. It can be clearly seen that the thermoplastic particles are fully phase-separated from the matrix in both systems as the measured fraction is quite close to the calculated value.

Table 1 Volume fraction and sizes of thermoplastic particles in modified epoxy. 


\begin{tabular}{lcccccc}
\hline & TGP5 & TGP10 & TGP15 & DP5 & DP10 & DP15 \\
\hline $\begin{array}{l}\text { Cotent in wt } \% \\
\text { Calculated }\end{array}$ & 5 & 10 & 15 & 5 & 10 & 15 \\
$\begin{array}{l}\text { content in vol\% } \\
\begin{array}{l}\text { Measured content } \\
\text { in vol\% }\end{array}\end{array}$ & 4.7 & 9.4 & 14.1 & 4.7 & 9.4 & 14.1 \\
$\begin{array}{l}\text { Average particle } \\
\text { size }\end{array}$ & $26.8 \pm 5.89 \mathrm{~nm}$ & $70.3 \pm 13.2 \mathrm{~nm}$ & $101 \pm 13.3 \mathrm{~nm}$ & $1.00 \pm 0.29 \mu \mathrm{m}$ & $1.14 \pm 0.21 \mu \mathrm{m}$ & $1.24 \pm 0.29 \mu \mathrm{m}$ \\
\hline
\end{tabular}
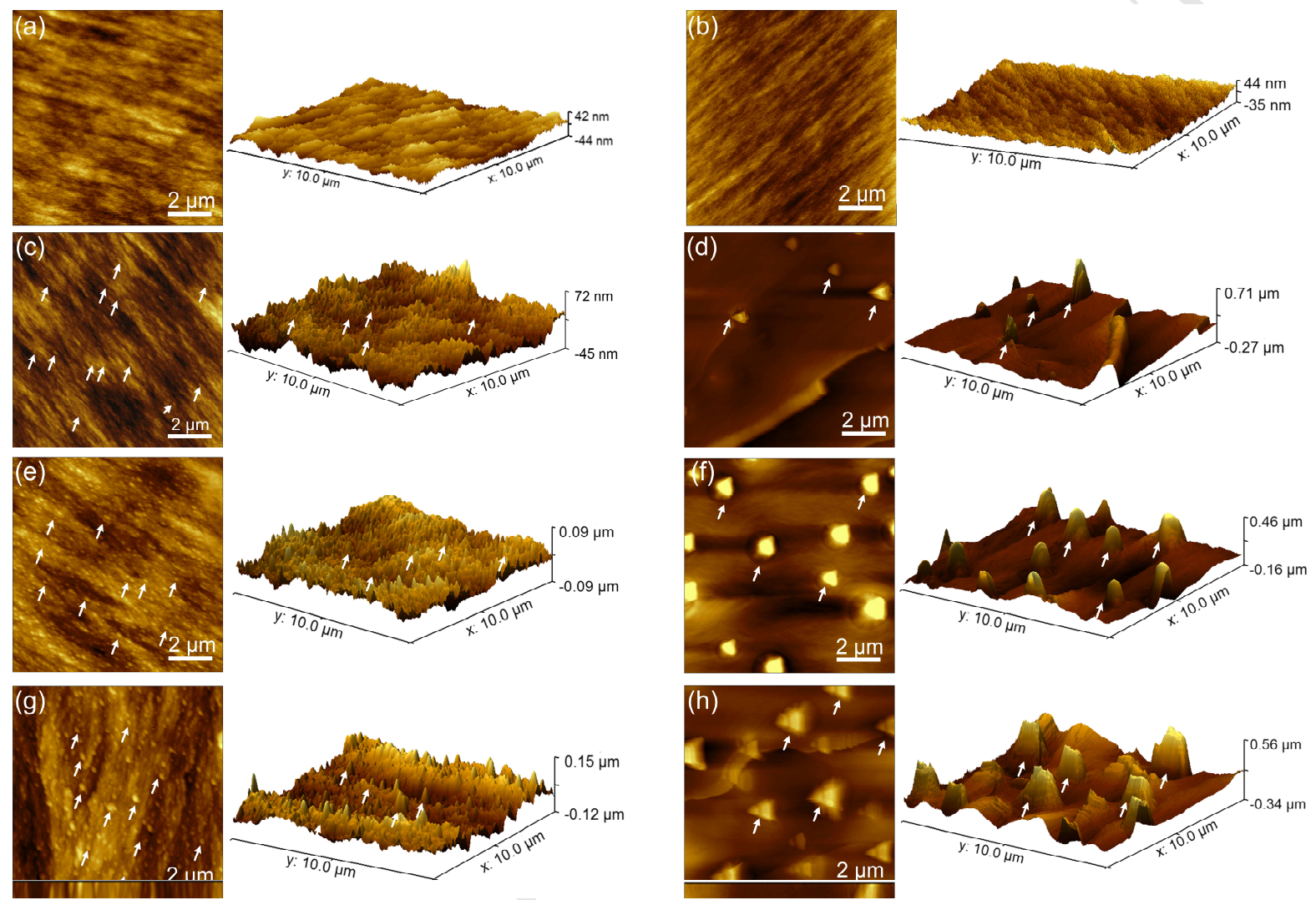

Figure. 1 AFM images of the fracture surfaces of the modified TP/epoxy blends with varying PEI content:(a) TGP0, (b) DP0, (c) TGP5, (d) DP5, (e) TGP10, (f) DP10, (g) TGP15 and (h) DP15.

The excessively rough fracture surface of the specimens with a PEI content of $20 \mathrm{wt} \%$ made it impossible to perform AFM analysis, so further investigations were carried out using electron microscopy. As seen in the micrographs of Figure 2, the $20 \mathrm{wt} \%$ TP modified systems (TGP20 and DP20) are remarkably different from each other both in terms of microstructure and particle size. A co-continuous morphology with inter-connected thermoplastic-rich phases is readily observed in both cases, however with an obvious difference in the relative size of the domains (Fig. 2a and $2 d$ ). The TP-rich phases in DP20 system, magnified in Fig. 2b, are, in fact, regions with large epoxy particles 


\section{ACCEPTED MANUSCRIPT}

dispersed in a thin-walled network of thermoplastic phase. This is an indication of a secondary phase separation or, more precisely, a local phase inversion during the curing reaction. This phenomenon had also been observed in a previous study where a different type of thermoplastic modifier was used [14]. In the case of PEI/TGDDM epoxy blends, both PEI-rich and epoxy-rich domains, as pointed in Fig. 2(d), have noticeably smaller sizes compared to those of the modified DGEBA. A rather similar secondary phase separation scenario is observed in these blends, as shown in the magnified section in Fig. 2(e) where submicron PEI particles could be identified in the rather smaller epoxy-rich islands as marked by the red dashed lines.
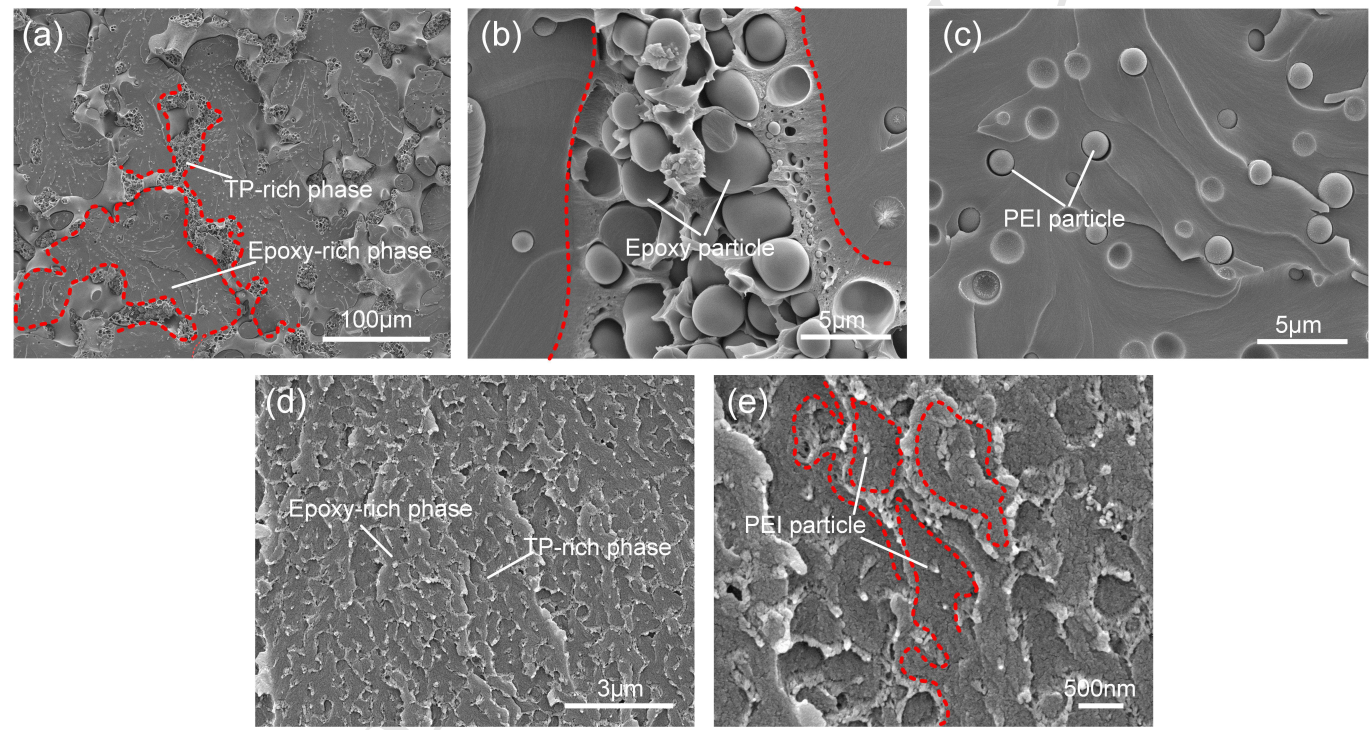

Figure 2. SEM micrographs of the TP/epoxy blends containing $20 \mathrm{wt} \%$ of PEI: (a) DP20, (b) PEI-rich zone of DP20, (c) epoxy-rich zone of DP20, (d) TGP20 and (e) enlarged PEI-rich phases of TGP20.

\subsection{Understanding the difference in morphologies}

It has been established that variables such as thermoplastic content and molecular weight of thermoplastic and curing profile may affect the phase morphology of the TP modified epoxy systems. However, what we noticed here is that even with similar TP content, under similar curing conditions, the resin system could alter the resulting phase morphology, as indicated by Fig. 1 and 2. Reactioninduced phase separation is controlled by both thermodynamic and kinetic factors. Miscibility of the 
modifier with the resin system is a thermodynamic parameter predominantly affecting the onset of phase separation. Conversion rate and rheological characteristics of the blend, on the other hand, are amongst the most important kinetic factors controlling the phase separation process. Conversion rate can control the termination of the process being usually associated with the gelation point $[17,34]$, and viscosity controls the phase separation rate as well as particle growth through diffusion or coalescence [21].

The above-mentioned parameters are therefore investigated to further clarify the underlying causes for the difference in the morphology of the two systems. Miscibility of polymers depends on the proximity of their solubility parameters. The higher the miscibility of the thermoplastic and the epoxy matrix, the longer it will take for the phase separation to start [35]. Solubility parameters of PEI, DGEBA epoxy and TGDDM epoxy resins are $17.4 \mathrm{MPa}^{1 / 2}, 21.26 \mathrm{MPa}^{1 / 2}$ and $21.84 \mathrm{MPa}^{1 / 2}$, respectively $[35,36]$. The quite similar values between DGEBA and TGDDM would suggest that there are no obvious differences about the occurrence of phase separation process in both systems.

Fig. 3 shows the degree of conversion as well as conversion rate of modified DGEBA and TGDDM systems obtained from DSC scans. Resin system based on the bifunctional epoxy show a higher degree of conversion during the curing cycle in comparison to the ones based on TGDDM epoxy (Fig. 3a). This is better observed by comparing the resulting conversion rates shown in Fig. $3 \mathrm{~b}$ where the difference in conversion rate manifests itself in a higher reaction rate before degree of conversion reaches 0.55 (well above gelation) and hence a shorter time for phase separation in DGEBA epoxy. This however cannot explain the smaller particle size in the modified tetrafunctional epoxy as the thermoplastic phase has a longer time for separation in TGDDM epoxy than in DGEBA epoxy. 

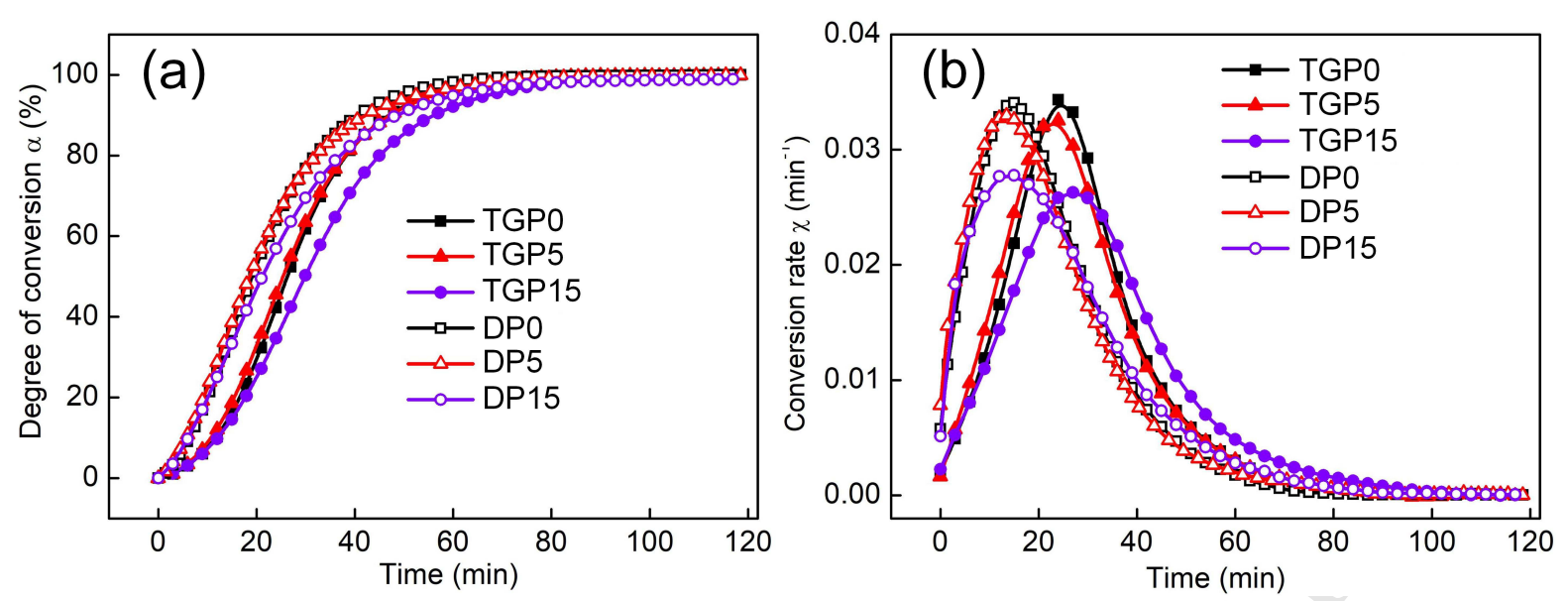

Figure 3. Degree of conversion (a) and conversion rate (b) of PEI modified DGEBA and TGDDM.

Fig. 4 compares the viscosity variations of the two modified epoxy blends as a function of temperature. All systems show a noticeable drop in viscosity up to a temperature range between 150$180^{\circ} \mathrm{C}$ above which a relatively stable viscosity is reached just before the start of the curing reaction. As expected, viscosities of the systems based on the tetrafunctional epoxy resin remain higher than the modified bifunctional epoxy systems over the measured temperature range. The difference is minimised at the stable region $\left(180-200^{\circ} \mathrm{C}\right)$ until the onset of curing reaction where the viscosity ramps up rapidly (not shown in the Fig. 4). Investigations using hot-stage microscopy revealed that thermoplastic phase separation starts at the very early stages of curing at a relatively high rate. The phase separation rate drops drastically, in a relatively short period of time, since the mobility and hence the growth of the phase-separated particles become increasingly limited due to the viscosity built-up. Similar trends have also been observed by other researchers $[17,37,38]$. This suggests that a significant part of particle formation happens at the very early stages of the reaction where the difference between the viscosities of the two systems will still be considerable (Fig. 4b). Higher viscosity impedes diffusion of the high molecular weight thermoplastic chains, which is necessary for the growth of the phase separated particles. In the meantime, the significantly denser cross-link in tetrafunctional epoxy is believed to be another reason for different phase morphologies observed following the termination of curing process since a greater number of cross-links could also suppress the diffusion of thermoplastic. 

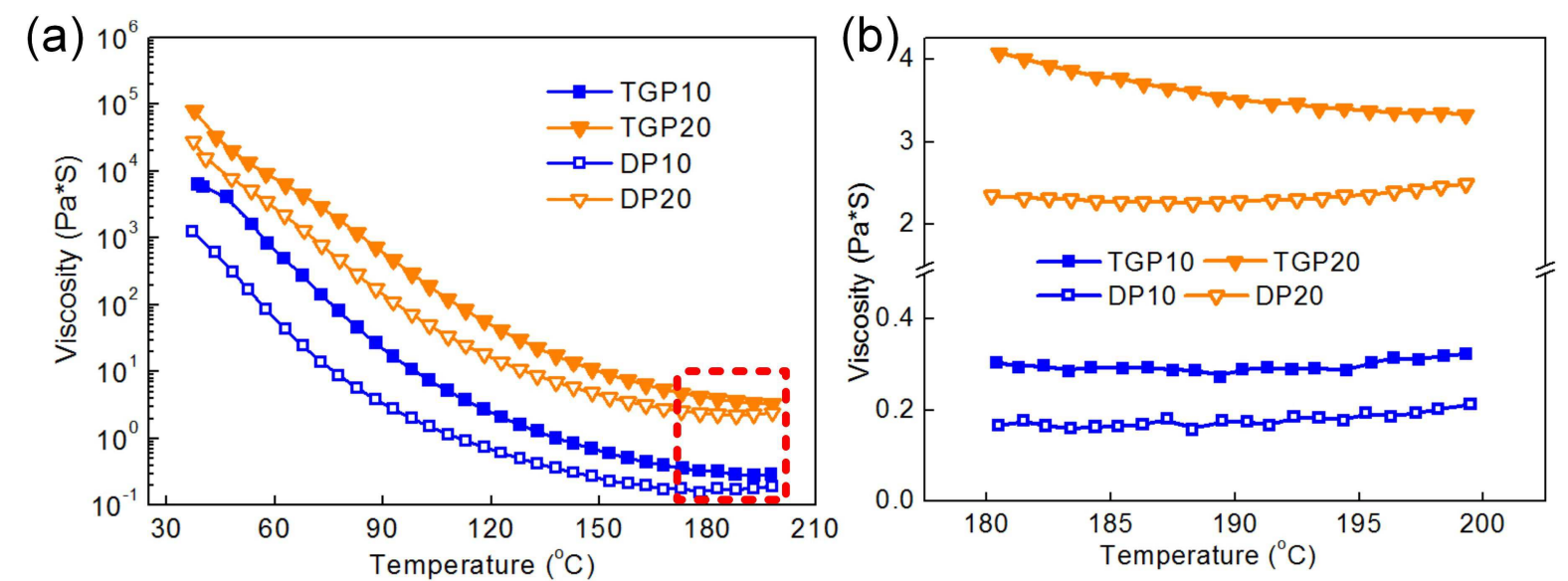

Figure 4. (a) Viscosity of modified epoxy resins as a function of temperature and (b) detailed variation of viscosity of modified epoxy resins at $180-200^{\circ} \mathrm{C}$ (enlarged dashed rectangle in (a)).

The noticeably higher heat generated during the curing reaction of the systems based on tetrafunctional epoxy, shown in Figure 5a, is an indication of a higher level of cross-linking. The latter can be directly calculated using equation 3 , as discussed earlier. The results are compared in Figure $5 \mathrm{~b}$ where again, the difference is clearly visible. In summary, the formation of submicron-sized TP particles in blends based on tetrafunctional epoxy is directly attributed to the higher viscosity as well as higher cross-link density of the resin system, leading to the distinct morphologies shown in Fig. 1 and 2 .
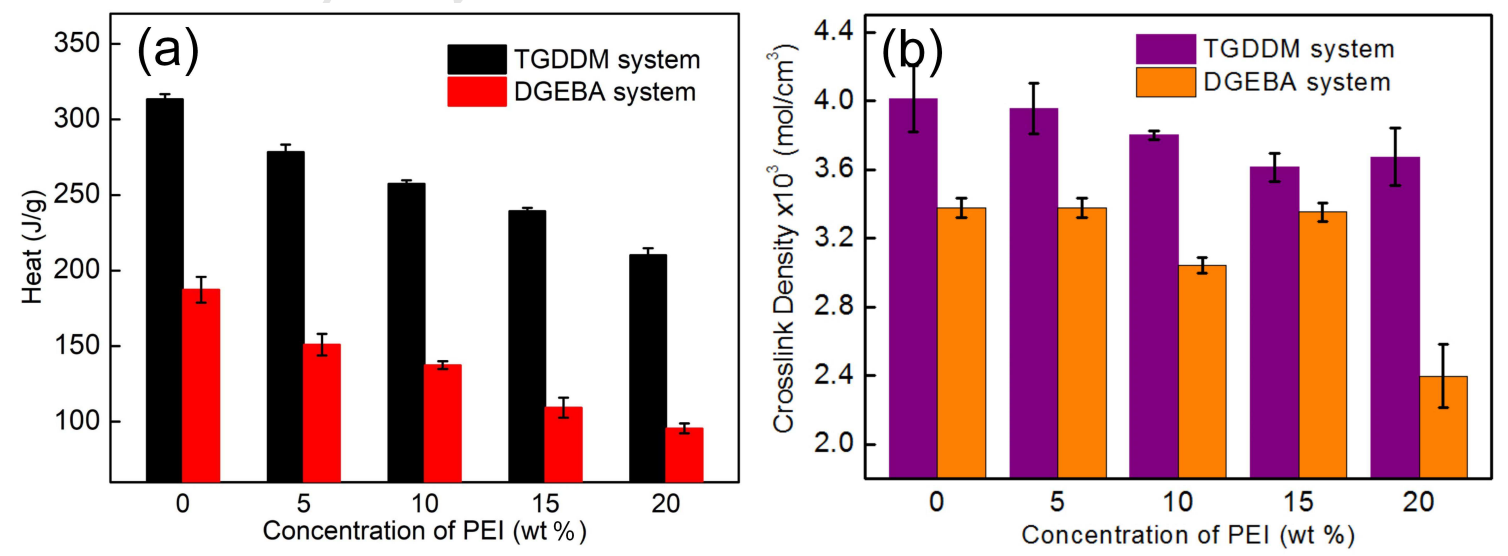

Figure 5. (a) Heat generated during the curing reaction of the PEI/epoxy blends and (b) cross-link density of the blends. 
Figure 6 represents a schematic of typical phase separation processes in both epoxy systems leading to a particulate morphology (corresponding to a PEI content between 5 and $15 \mathrm{wt} \%$ ). Initially, the epoxy monomers, hardener molecules and thermoplastic chains form a homogeneous solution. Phase separation starts following the curing reaction. Phase-separated TP particles then grow through diffusion and coalescence [21]. As discussed earlier, particle growth through diffusion will be more limited in the tetrafunctional epoxy system due to the combined effects of a higher viscosity and cross-link density (Fig. 4 and 5). Additionally, the viscosity of epoxy resin also increases significantly and rapidly upon the curing reaction, further limiting the growth of thermoplastic particles. This results in the formation of significantly much smaller sized particles in the modified TGDDM epoxy systems.
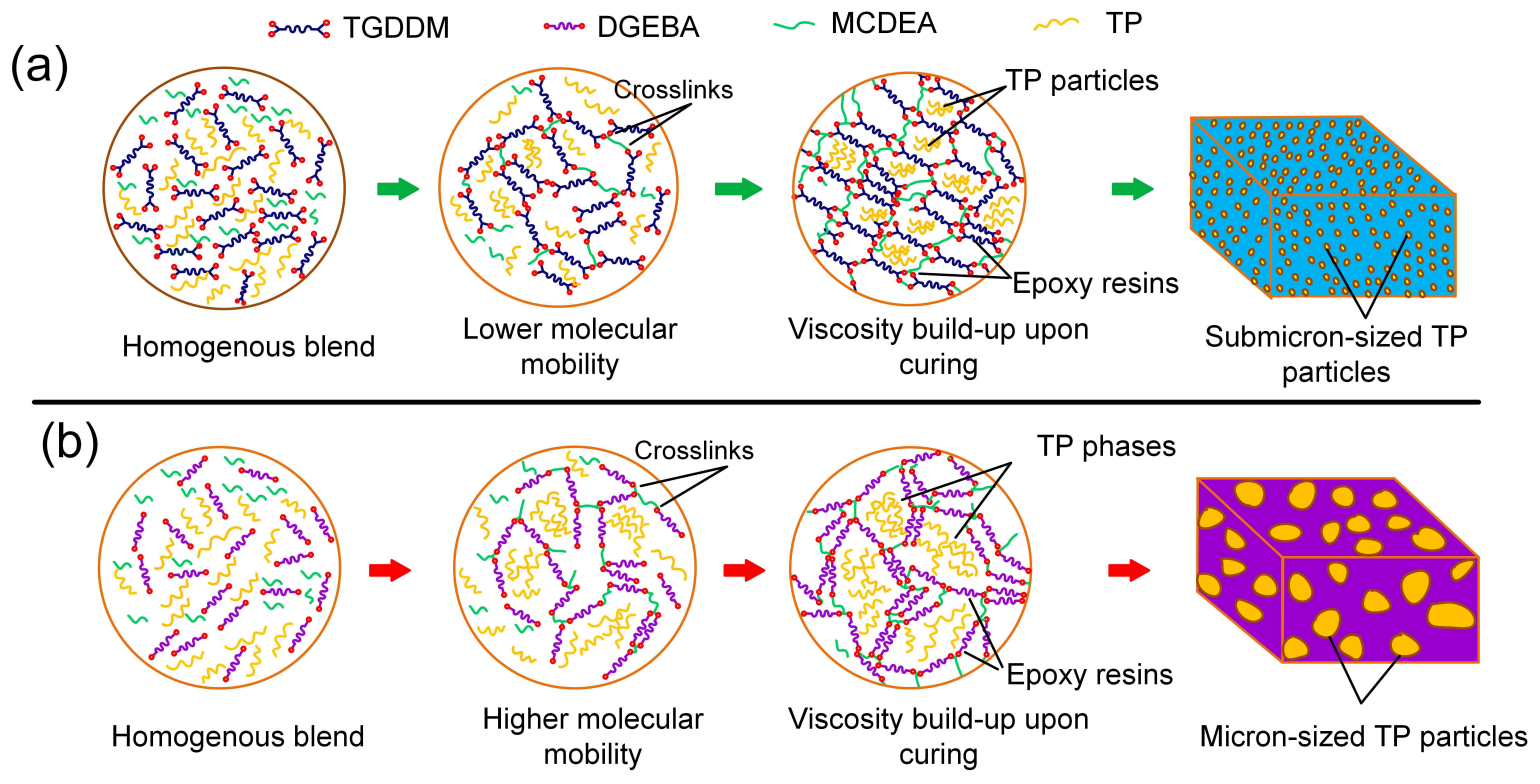

Figure 6. Illustration of phase morphology evolution of particulate structure of PEI modified epoxy resins: (a) PEI modified TGDDM and (b) PEI modified DGEBA.

\subsection{Mode-I fracture toughness of PEI modified epoxy systems}


Figure 7 compares the mode-I fracture toughness of the cured PEI modified epoxy blends in terms of stress intensity factor, $K_{I C}$ (Fig.7a) and the resulting critical strain energy release rate (also known as fracture energy), $G_{I C}$ (Table 2). A monotonic increase in the $K_{I C}$ and $G_{I C}$ of both modified epoxy systems with thermoplastic content is readily observed with a noticeable jump for the modified epoxy with $20 \mathrm{wt} \%$ PEI (DP20 and TGP20). This is consistent with the transition in the morphology from a particulate to co-continuous as discussed in the previous section and shown in Fig. 2.

The increase in the $G_{I C}$ of the blends, based on bifunctional epoxy, is more significant than the tetrafunctional counterparts at similar thermoplastic content, as better observed in Fig. $7 \mathrm{~b}$ where the differences between the fracture energies of the modified and unmodified systems, $\Delta G_{I C}$, in different blends are compared. Fractography of the fracture surfaces helps us to gain a better understanding of the underlying reasons for the observed differences.
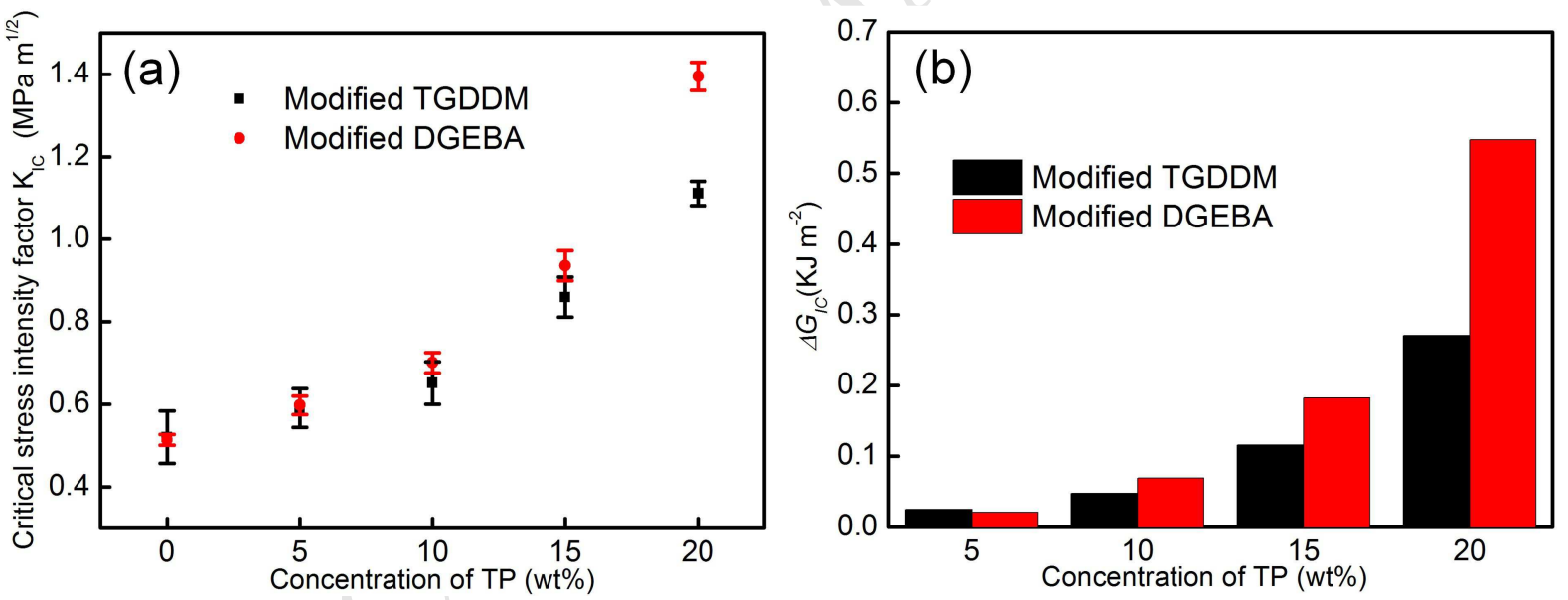

Figure 7. (a) Critical stress intensity factor, $K_{I C}$ and (b) increase in fracture energy, $\Delta G_{I C}$, of modified epoxy blends at different PEI contents.

Table 2 Mode-I fracture toughness of PEI modified epoxy systems.

\begin{tabular}{ccccccc}
\hline Epoxy system & & $K_{I C}\left(\mathrm{MPa} \cdot \mathrm{m}^{1 / 2}\right)$ & $K_{I C} / K_{I C, u}{ }^{1}$ & $G_{I C}\left(\mathrm{KJ} \cdot \mathrm{m}^{-2}\right)$ & $G_{I C} / G_{I C, u}{ }^{2}$ & $\Delta G_{I C}\left(\mathrm{KJ} \cdot \mathrm{m}^{-2}\right)$ \\
\hline \multirow{2}{*}{ TGDDM } & TGP0 & $0.52 \pm 0.06$ & - & $0.06 \pm 0.02$ & - & 0 \\
& TGP5 & $0.59 \pm 0.05$ & 1.14 & $0.09 \pm 0.01$ & 1.50 & 0.03 \\
& TGP10 & $0.65 \pm 0.05$ & 1.25 & $0.11 \pm 0.02$ & 1.83 & 0.05 \\
\hline
\end{tabular}




\section{ACCEPTED MANUSCRIPT}

\begin{tabular}{ccccccc}
\hline & TGP15 & $0.86 \pm 0.05$ & 1.65 & $0.18 \pm 0.02$ & 3.00 & 0.12 \\
& TGP20 & $1.11 \pm 0.03$ & 2.14 & $0.33 \pm 0.01$ & 5.50 & 0.27 \\
& DP0 & $0.51 \pm 0.01$ & - & $0.10 \pm 0.01$ & - & 0 \\
& DP5 & $0.60 \pm 0.02$ & 1.18 & $0.12 \pm 0.01$ & 1.20 & 0.02 \\
DGEBA & DP10 & $0.70 \pm 0.02$ & 1.37 & $0.17 \pm 0.02$ & 1.70 & 0.07 \\
& DP15 & $0.94 \pm 0.04$ & 1.84 & $0.28 \pm 0.02$ & 2.80 & 0.18 \\
& DP20 & $1.39 \pm 0.03$ & 2.73 & $0.65 \pm 0.03$ & 6.50 & 0.55 \\
\hline
\end{tabular}

${ }^{1} K_{I C, u}$ is the critical stress intensity factor of unmodified epoxy.

${ }^{2} G_{I C, u}$ is the critical strain energy release rate of unmodified epoxy. 

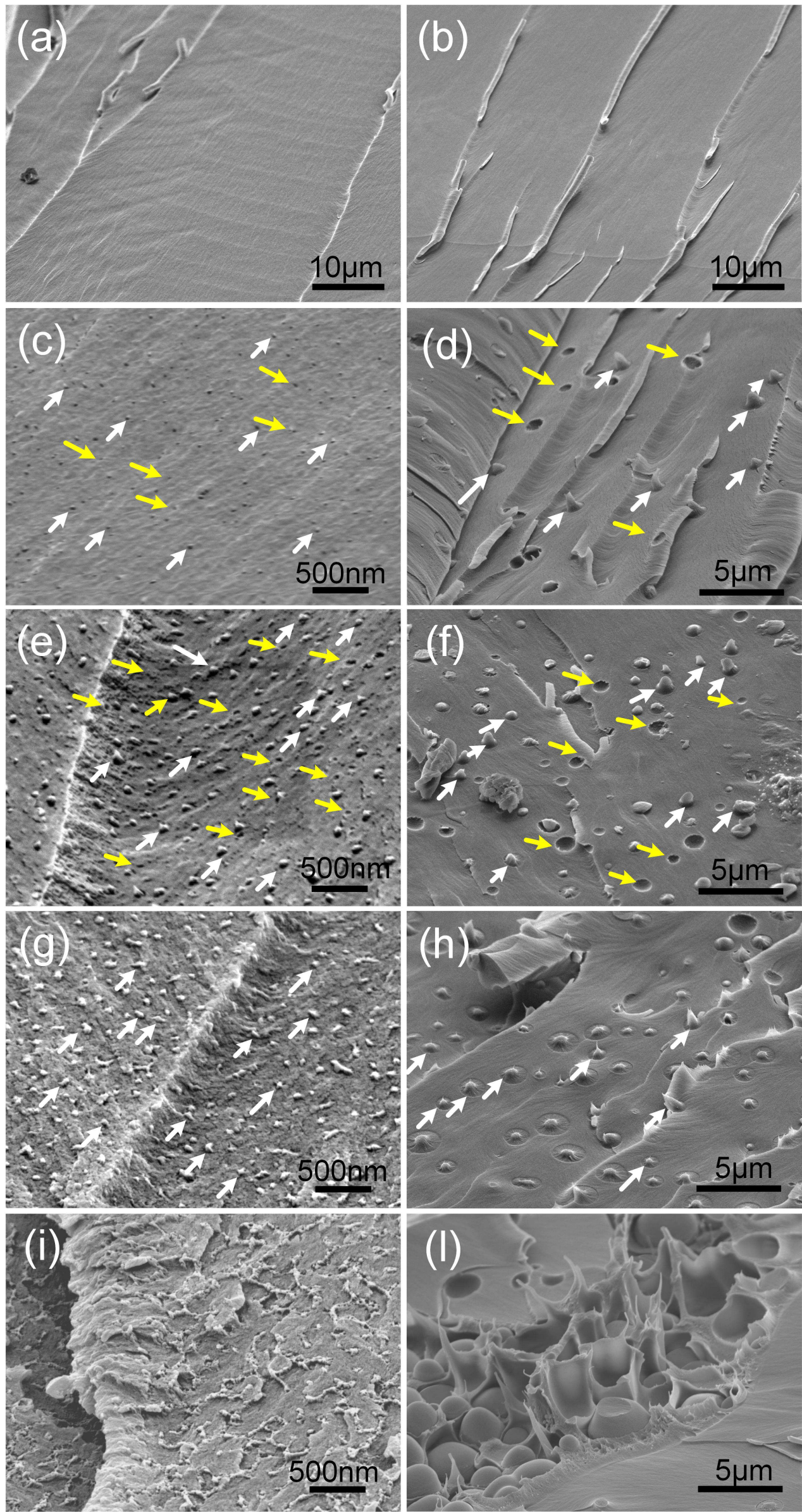
Figure 8. Fracture surfaces of modified epoxy blends at different PEI contents: (a) TGP0, (b) DP0, (c) TGP5, (d) DP5, (e) TGP10, (f) DP10, (g) TGP15, (h) DP15, (i) TGP20 and (l) DP20.

SEM micrographs of the fracture surfaces of the post-failure SENB specimens are shown in Fig. 8. Both unmodified epoxy resins demonstrate a rather featureless fracture surface (Fig 8a and 9b), being a typical characteristic of brittle fracture. Fracture surfaces of the modified epoxy systems exhibit distinguishing features arising from the deformed thermoplastic phases (shown by white arrows), together with cavitation voids (identified by yellow arrows). The extent of these features varies significantly from one system to another. For instance, limited numbers of particle cavitation voids are visible in systems containing $15 \mathrm{wt} \%$ PEI (DP15 and TGP15). This confirms that in these systems, the bridging of thermoplastic is one of the most dominant energy dissipation mechanisms in the event of crack.

Mirroring faces of the fracture surfaces for each toughened blend were identified as shown in Fig. 9. The numbers on the left and right micrographs of each pair correspond to similar locations on both sides of the fracture surface. This was carried out only for the bifunctional epoxy systems where matching the faces was more feasible than the ones based on the tetrafunctional epoxy with significantly smaller TP phases. Cavitation voids in blends containing $5 \mathrm{wt} \%$ PEI can be matched to deformed TP particles on the opposite face indicating that debonding after initial plastic deformation (stretching) of the TP phase (Fig. 9a and b) has occurred. As for the blends containing $10 \mathrm{wt} \%$ PEI (DP10) a new feature starts to appear which is characterised by particle fracture following plastic deformation, although in most cases, crack propagation leaves a clean cavitation hole on either side, similar to the DP5 blends. Some examples are indicated in Fig. 9c and d using yellow circles. This feature is observed more frequently in DP15 and DP20 where most particles (continuous TP phases in DP20) fracture following plastic deformation. Similar behaviour could be observed in the blends based on tetrafunctional epoxy resin as shown in Fig. 8 where cavitation voids and stretched TP particles are indicated by yellow and white arrows respectively. 


\section{ACCEPTED MANUSCRIPT}
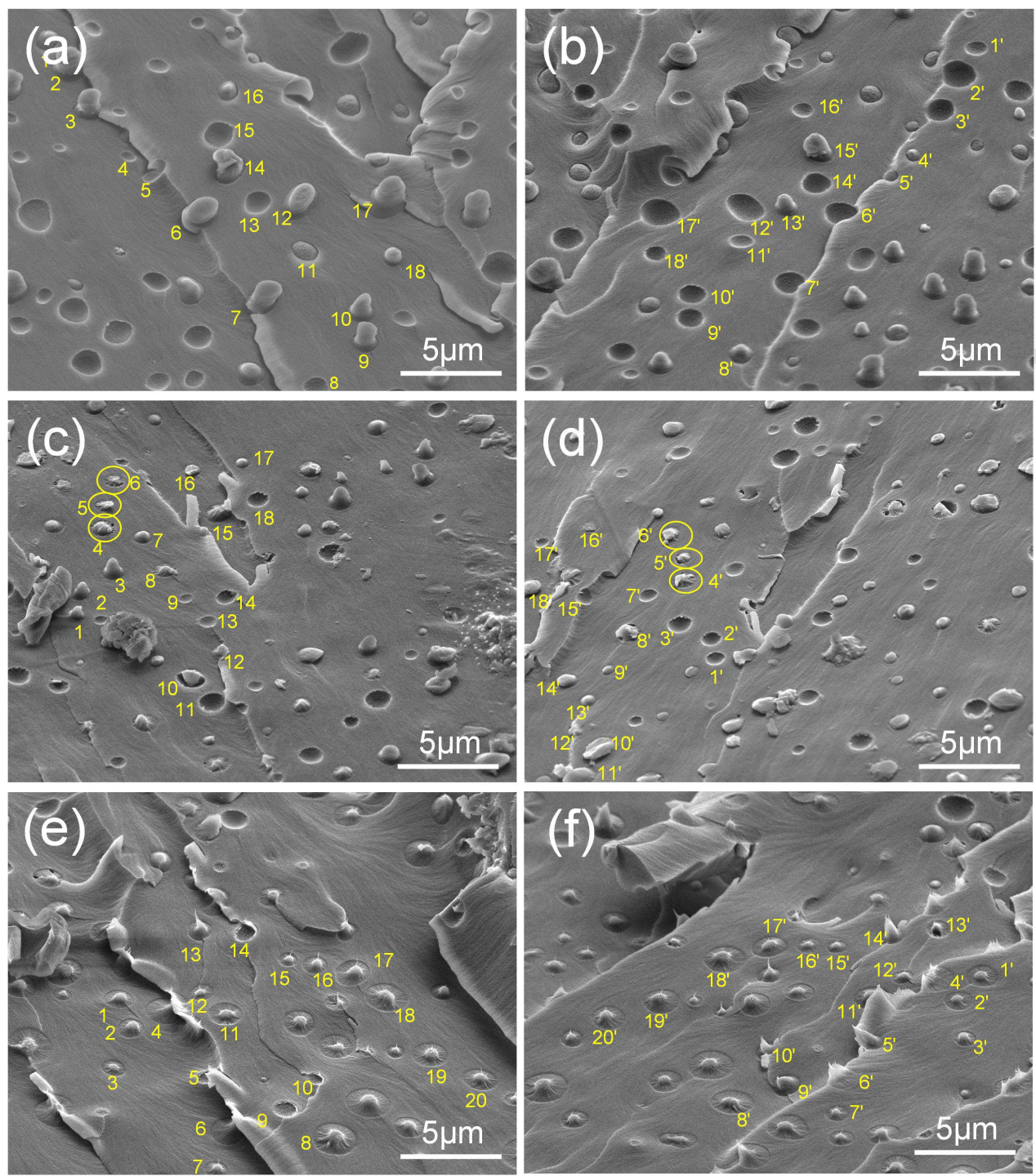

Figure 9. The fracture morphology of modified epoxy resins at the same position: (a) and (b) DP5, (c) and (d) DP10 and (e) and (f) DP15.

The interaction of TP particles with a propagating crack is illustrated schematically in Fig. 10 where both scenarios leading to either TP debonding or rupture are depicted. The top row shows the prevailing fracture mechanism in blends at a lower TP content $(\leq 10 \mathrm{wt} \%)$ where PEI particles deform and then debond from the epoxy matrix. The bottom part demonstrates plastic deformation and subsequent rupture of the PEI particles in blends at higher PEI concentration $(\geq 15 \mathrm{wt} \%)$. 


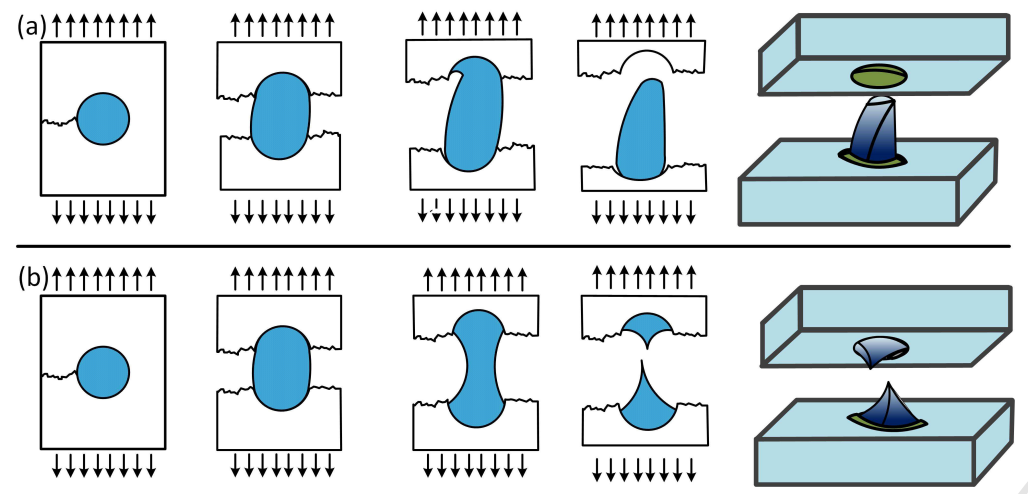

Figure 10. The fracture behaviour of thermoplastic particles in modified epoxy resins with different TP concentrations: (a) de-bonding from the matrix, (b) rupture of TP particles.

It has been well established that particle cavitation and plastic deformation could significantly reduce stress triaxiality of the advancing crack in the matrix under plane strain conditions [39]. The resulting non-homogeneous stress state enhances the likelihood of shear yielding in the brittle matrix resulting in localised regions of plastic deformation in the epoxy matrix known as shear bands, typically starting at one particle and ending at another [14,40]. Shear bands are more noticeable in the blends containing a higher content of PEI (TGP15 and DP15). The rather wrinkled texture of the fracture surfaces observed in Fig. 8 and 9 is indicative of shear bands. This is most probably due to a higher degree of plastic deformation and yielding of the thermoplastic particles in these blends causing further non-uniformity in the stress distribution ahead of the crack tip, and hence an increased shear. Moreover, shear band formation is known to be more prevalent in the presence of a higher volume fraction of dispersed particles where a stress-field overlap between the neighbouring particles exists. Consequently, it can be concluded that the bridging of thermoplastic and the shear banding of the matrix are the two major energy dissipating mechanisms that contribute to the measured fracture toughness enhancement.

In comparison with the tetrafunctional epoxy (TGDDM), the TP particles in bifunctional epoxy blends show a higher degree of plastic deformation following crack propagation (Fig. 8d, $\mathrm{f}$ and h) which could well be an indication of a higher degree of energy dissipation in crack propagation. Moreover, as shear banding is related to the ductility of the matrix, TP modified blends based on the 
more ductile bifunctional (DGEBA) epoxy would have a higher chance of shear banding during crack propagation than the ones based on the tetrafunctional epoxy at similar TP content (Table 1). This could explain the higher fracture toughness enhancement in DGEBA blends. The other observation is a much more pronounced TP deformation in epoxy blends with a co-continuous thermoplastic phase (20 wt\% TP content), as shown in Fig. $8 \mathrm{i}$ and 1, leading to a higher level of increase in fracture toughness for TGP20 and DP20 blends.

\section{Concluding remarks}

Phase morphology and fracture behaviour of PEI modified epoxy blends based on two different types of epoxy systems, namely bifunctional (DGEBA) and tetrafunctional (TGDDM) were investigated and the following conclusion is drawn:

(1) A particle-matrix morphology was dominant morphology in the blends with a PEI content up to 15 wt\% above which a multiphase structure consisting of mainly co-continuous phases was observed, following reaction-induced phase separation (RIPS).

(2) TP particle size was considerably smaller in the PEI modified epoxy blends based on the tetrafunctional epoxy (TGDDM). Higher viscosity and cross-link density of these resins were considered to be the main factors restricting the mobility of the polymer molecules, and hence diffusion growth of the particles during the course of the phase separation process. This eventually led to different degrees of improvement in fracture toughness.

(3) Increasing the PEI content in the modified blends, resulted in an increase in the value of the fracture toughness. A sharper increase was noticed at the highest PEI content (20 wt $\%)$ in both systems where the existence of a co-continuous morphology was established.

(4) Different fracture behaviour, and hence energy dissipation mechanisms, was observed following a fractography study of the fracture surfaces. Plastic deformation (stretching) of the phaseseparated particles, followed by complete debonding, was the main feature observed in blends at lower TP content $(\leq 10 \mathrm{wt} \%)$. Particle deboning was found to be replaced, nearly completely, 
with particle rupture following plastic deformation at the PEI content of $15 \mathrm{wt} \%$ and above in both epoxy systems. Plastic deformation and debonding or tearing (crack bridging) together with shear banding were found to be the prevailing energy dissipation mechanisms leading to the measured enhancements in fracture toughness of the modified blends.

\section{Acknowledgements}

The authors would also like to gratefully acknowledge the funding from the Queen's University Belfast/China Scholarship Council (QUB/CSC) PhD Scholarship.

\section{References}

[1] S. Liu, X. Fan, C. He, Improving the fracture toughness of epoxy with nanosilica-rubber coreshell nanoparticles, Compos. Sci. Technol. $125 \quad$ (2016) 132-140. doi:10.1016/j.compscitech.2016.01.009.

[2] Y. Wang, S. Kumar, R. Pillai, J. Che, M.B. Chan-Park, High Interlaminar Shear Strength Enhancement of Carbon Fiber/ Epoxy Composite through Fiber-and Matrix-Anchored Carbon Nanotube Networks, ACS Appl. Mater. Interfaces. 9 (2017) 8960-8966. doi:10.1021/acsami.6b13197.

[3] S. Nagendiran, M. Alagar, I. Hamerton, Octasilsesquioxane-reinforced DGEBA and TGDDM epoxy nanocomposites: Characterization of thermal, dielectric and morphological properties, Acta Mater. 58 (2010) 3345-3356. doi:10.1016/j.actamat.2010.02.008.

[4] E. Borowski, E. Soliman, U. Kandil, M. Taha, Interlaminar Fracture Toughness of CFRP Laminates Incorporating Multi-Walled Carbon Nanotubes, Polymers (Basel). 7 (2015) 10201045. doi:10.3390/polym7061020.

[5] S. Kobayashi, J. Kitagawa, Effect of fine particle incorporation into matrix on mechanical properties of plain woven carbon fiber reinforced plastics fabricated with vacuum assisted resin transfer molding, Compos. Part B Eng. 85 (2016) 31-40. doi:10.1016/j.compositesb.2015.09.020.

[6] L. Guan, L.L. Gong, L. Tang, L. Wu, J. Jiang, G. Lai, Mechanical properties and fracture behaviors of epoxy composites with phase-separation formed liquid rubber and preformed powdered rubber nanoparticles: A comparative study, Polym. Compos. 36 (2015) 785-799. doi:10.1002/pc.22995.

[7] J. Parameswaranpillai, N. Hameed, J. Pionteck, E.M. Woo, Handbook of Epoxy Blends, 
Springer International Publishing, Cham, 2017. doi:10.1007/978-3-319-40043-3.

[8] S. Thomas, C. Sinturel, R. Thomas, Micro- and Nanostructured Epoxy/Rubber Blends, WileyVCH Verlag GmbH \& Co. KGaA, Weinheim, Germany, 2014. doi:10.1002/9783527666874.

[9] D. Ratna, G.P. Simon, Mechanical characterization and morphology of carboxyl randomized poly(2-ethyl hexyl acrylate) liquid rubber toughened epoxy resins, Polymer (Guildf). 42 (2001) 7739-7747. doi:10.1016/S0032-3861(01)00278-6.

[10] D. Quan, A. Ivankovic, Effect of core-shell rubber (CSR) nano-particles on mechanical properties and fracture toughness of an epoxy polymer, Polymer (Guildf). 66 (2015) 16-28. doi:10.1016/j.polymer.2015.04.002.

[11] A. Keller, H.M. Chong, A.C. Taylor, C. Dransfeld, K. Masania, Core-shell rubber nanoparticle reinforcement and processing of high toughness fast-curing epoxy composites, Compos. Sci. Technol. 147 (2017) 78-88. doi:10.1016/j.compscitech.2017.05.002.

[12] D. Ratna, Phase separation in liquid rubber modified epoxy mixture. Relationship between curing conditions, morphology and ultimate behavior, Polymer (Guildf). 42 (2001) 4209-4218. doi:10.1016/S0032-3861(00)00798-9.

[13] C. Su, E. Woo, Cure kinetics and morphology of amine-cured tetraglycidyl-4, 4'diaminodiphenylmethane epoxy blends with poly (ether imide), Polymer (Guildf). 36 (1995) 2883-2894. http://www.sciencedirect.com/science/article/pii/003238619594337S.

[14] M. Aravand, S. V. Lomov, L. Gorbatikh, Morphology and fracture behavior of POM modified epoxy matrices and their carbon fiber composites, Compos. Sci. Technol. 110 (2015) 8-16. doi:10.1016/j.compscitech.2015.01.017.

[15] C.B. Bucknall, A.H. Gilbert, Toughening tetrafunctional epoxy resins using polyetherimide, Polymer (Guildf). 30 (1989) 213-217. doi:10.1016/0032-3861(89)90107-9.

[16] W. Chen, Z. Tao, L. Fan, S. Yang, W. Jiang, J. Wang, Y. Xiong, Effect of poly(etherimide) chemical structures on the properties of epoxy/poly(etherimide) blends and their carbon fiberreinforced composites, J. Appl. Polym. Sci. 119 (2011) 3162-3169. doi:10.1002/app.32916.

[17] W. Gan, W. Xiong, Y. Yu, S. Li, Effects of the molecular weight of poly(ether imide) on the viscoelastic phase separation of poly(ether imide)/epoxy blends, J. Appl. Polym. Sci. 114 (2009) 3158-3167. doi:10.1002/app.30897.

[18] R.D. Brooker, A.J. Kinloch, A.C. Taylor, The Morphology and Fracture Properties of Thermoplastic-Toughened Epoxy Polymers, J. Adhes. $86 \quad$ (2010) 726-741. doi:10.1080/00218464.2010.482415. 
[19] Y. Yu, Z. Zhang, W. Gan, M. Wang, S. Li, Effect of polyethersulfone on the mechanical and rheological properties of polyetherimide-modified epoxy systems, Ind. Eng. Chem. Res. 42 (2003) 3250-3256. doi:10.1021/ie0210309.

[20] P.A. Oyanguren, M.J. Galante, K. Andromaque, P.M. Frontini, R.J.J. Williams, Development of bicontinuous morphologies in polysulfone-epoxy blends, Polymer (Guildf). 40 (1999) 5249-5255. doi:10.1016/S0032-3861(98)00742-3.

[21] S. Goossens, B. Goderis, G. Groeninckx, Reaction-induced phase separation in crystallizable micro- and nanostructured high melting thermoplastic/epoxy resin blends, Macromolecules. 39 (2006) 2953-2963. doi:10.1021/ma052742o.

[22] G. Vanden Poel, S. Goossens, B. Goderis, G. Groeninckx, Reaction induced phase separation in semicrystalline thermoplastic/epoxy resin blends, Polymer (Guildf). 46 (2005) 1075810771. doi:10.1016/J.POLYMER.2005.09.013.

[23] G. Yu, P. Wu, Effect of chemically modified graphene oxide on the phase separation behaviour and properties of an epoxy/polyetherimide binary system, Polym. Chem. 5 (2014) 96-104. doi:10.1039/C3PY00878A.

[24] J. Zhang, X. Xie, Influence of addition of silica particles on reaction-induced phase separation and properties of epoxy/PEI blends, Compos. Part B Eng. 42 (2011) 2163-2169. doi:10.1016/j.compositesb.2011.05.013.

[25] W. Li, Z. Xia, A. Li, Y. Ling, B. Wang, W. Gan, Effect of SiO 2 nanoparticles on the reactioninduced phase separation in dynamically asymmetric epoxy/PEI blends, RSC Adv. 5 (2015) 8471-8478. doi:10.1039/C4RA12261E.

[26] S. Grishchuk, O. Gryshchuk, M. Weber, J. Karger-Kocsis, Structure and toughness of polyethersulfone (PESU)-modified anhydride-cured tetrafunctional epoxy resin: Effect of PESU molecular mass, J. Appl. Polym. Sci. 123 (2012) 1193-1200. doi:10.1002/app.34610.

[27] J. Cho, J. Hwang, K. Cho, J. An, C. Park, Effects of morphology on toughening of tetrafunctional epoxy resins with poly (ether imide), Polymer (Guildf). (1993) 1-5. http://www.sciencedirect.com/science/article/pii/003238619390005U.

[28] J.H. Hodgkin, G.P. Simon, R.J. Varley, Thermoplastic Toughening of Epoxy Resins: a Critical Review, Polym. Adv. Technol. 9 (1998) 3-10. doi:10.1002/(SICI)10991581(199801)9:1<3::AID-PAT727>3.0.CO;2-I.

[29] A.C. Garg, Y.W. Mai, Failure mechanisms in toughened epoxy resins-A review, Compos. Sci. Technol. 31 (1988) 179-223. doi:10.1016/0266-3538(88)90009-7. 
[30] Y.L. Liang, R.A. Pearson, Toughening mechanisms in epoxy-silica nanocomposites (ESNs), Polymer (Guildf). 50 (2009) 4895-4905. doi:10.1016/j.polymer.2009.08.014.

[31] V.K. Josep, Paint and Coating Testing Manual, 1995. doi:10.1002/col.5080200415.

[32] A.C. Grillet, J. Galy, J.F. Gérard, J.P. Pascault, Mechanical and viscoelastic properties of epoxy networks cured with aromatic diamines, Polymer (Guildf). 32 (1991) 1885-1891. doi:10.1016/0032-3861(91)90380-2.

[33] J.K. Yeo, L.H. Sperling, D.A. Thomas, Rubber elasticity of poly(n-butyl acrylate) networks formed with multifunctional crosslinkers, J. Appl. Polym. Sci. 26 (1981) 3977-3993. doi:10.1002/app.1981.070261202.

[34] C.B. Bucknall, I.K. Partridge, Phase separation in epoxy resins containing polyethersulphone, Polymer (Guildf). 24 (1983) 639-644. doi:10.1016/0032-3861(83)90120-9.

[35] C.M. Hansen, Hansen solubility parameters : a user’s handbook., CRC Press, 2007.

[36] S. van der Zwaag, Self Healing Materials: An Alternative Approach to 20 Centuries of Materials Science, Springer, 2007. doi:10.1007/s13398-014-0173-7.2.

[37] W. Gan, Y. Yu, X. Liu, M. Wang, S. Li, Kinetics of phase separation at the early stage of spinodal decomposition in epoxy resin modified with PEI blends, Colloid Polym. Sci. 287 (2009) 23-28. doi:10.1007/s00396-008-1944-5.

[38] W. Gan, Y. Yu, M. Wang, Q. Tao, S. Li, Morphology Evolution during the Phase Separation of Polyetherimide/Epoxy Blends, Macromol. Rapid Commun. 24 (2003) 952-956. doi:10.1002/marc.200300017.

[39] H.J. Sue, R.A. Pearson, A.F. Yee, Mechanical modeling of initiation of localized yielding under plane stress conditions in rigid-rigid polymer alloys, Polym. Eng. Sci. 31 (1991) 793802. doi:10.1002/pen.760311106.

[40] Y. Huang, A.J. Kinloch, Modeling of the Toughening Mechanisms in Rubber-Modified Epoxy Polymers .2. a Quantitative Description of the Microstructure Fracture Property Relationships, J. Mater. Sci. 27 (1992) 2763-2769. doi:10.1007/BF00540703. 


\section{Highlights}

Phase morphology of thermoplastic modified different epoxy resins was investigated.

Functionality of epoxy had great impact on phase morphology of modified epoxy.

Modified epoxy with different functionality presented different fracture toughness.

Energy dissipation mechanisms of different modified epoxy resin were clarified. 